\title{
IL-23 induces the Expression of Pro-osteogenic Factors in Osteoclasts
}

\section{IL-23 induziert die Expression pro-osteogener Faktoren in Osteoklasten}

Authors

Dan-Dan Pang ${ }^{1,2^{*}}$, Li Cai2 ${ }^{*}$, Jing-Ru Zhang1,3, Sheng-Ming Dai²

\section{Affiliations}

1 Department of Rheumatology \& Immunology, Changhai Hospital, Second Military Medical University, Shanghai, China

2 Department of Rheumatology \& Immunology, Shanghai Jiao Tong University Affiliated Sixth People's Hospital, Shanghai, China

3 Department of Rheumatology \& Immunology, First Affiliated Hospital of Zhejiang Chinese Medical University, Hangzhou, China

Key words IL-23, osteoclasts, ankylosing spondylitis, Ephrin B2, sphingosine kinase 1

\section{Schlüsselwörter}

IL-23, Osteoklasten, Spondylitis ankylosans, Ephrin B2, Sphingosinkinase 1

Online publiziert: 11.2 .2020

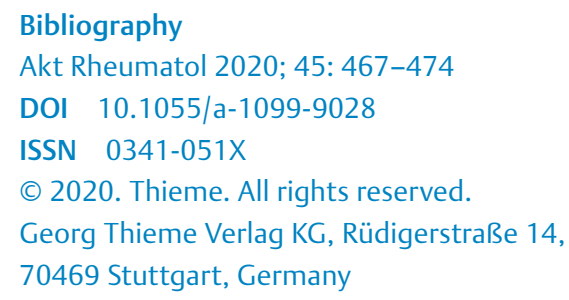

\section{ABSTRACT}

Background The mechanism for the new bone formation in ankylosing spondylitis (AS) is still unclear. Although it has been

*These two authors contributed equally to this research. demonstrated that IL-23 plays a pivotal role in the pathophysiology of AS, IL-23 has no direct effects on osteoblasts but modulates the function of osteoclasts.

Aims To explore whether IL-23 indirectly facilitates new bone formation through osteoclasts in AS, here we analyzed whether IL-23 enhances the expression levels of pro-osteogenic factors by osteoclasts.

Methods Mononuclear cells were harvested from mouse bone marrow and cultured in the presence of M-CSF $(50 \mathrm{ng} / \mathrm{ml})$ and RANKL $(30 \mathrm{ng} / \mathrm{ml}$ ) to trigger the production of osteoclasts. Protein and mRNA expression levels of Semaphorin 4D, Ephrin B2, BMP2, BMP6, SPHK1, HtrA1 and Wnt10b were measured using Western blot and qRT-PCR.

Results Primary mononuclear cells were transformed into osteoclasts with RANKL and M-CSF. The increased expression of NFATC1 and TRAP together with TRAP staining of $>3$ nuclei were used to identify mature osteoclasts. The mRNA expression levels of BMP2, Ephrin B2 and SPHK1 were enhanced by $1.46,2.1$ and 2.46 folds after exposure to IL-23. Confirmation of increased levels of Ephrin B2 and SPHK1 in IL-23-stimulated osteoclasts was provided by Western blot analysis. IL-23 had no effects on the expression of BMP6 or Wnt10b, or on the anti-osteogenic factors Semaphorin 4D or HtrA1.

Conclusions IL-23 induces osteoclasts to express pro-osteogenic factors rather than anti-osteogenic factors, suggesting IL-23 might indirectly promote the differentiation of osteoblasts through activated osteoclasts in ankylosing spondylitis.

\section{ZUSAMMENFASSUNG}

Hintergrund Der Mechanismus der Knochenneubildung bei ankylosierender Spondylitis (AS) ist nach wie vor unklar. Es wurde zwar nachgewiesen, dass IL-23 in der Pathophysiologie von AS eine zentrale Rolle spielt, doch IL-23 hat keine direkten Auswirkungen auf Osteoblasten, sondern moduliert die Funktion von Osteoklasten.

Ziele Es sollte untersucht werden, ob IL-23 bei AS indirekt eine Knochenneubildung durch Osteoklasten begünstigt. In diesem Zusammenhang wurde analysiert, ob IL-23 die Expressionsniveaus pro-osteogener Faktoren durch Osteoklasten steigert. Methoden Es wurden mononukleäre Zellen aus dem Knochenmark von Mäusen gewonnen, die zur Auslösung der Produktion von Osteoklasten in Gegenwart von M-CSF (50 ng/ml) 
und RANKL (30 ng/ml) kultiviert wurden. Mithilfe von WesternBlots und qRT-PCR wurden die Protein- und mRNA-Expressionsniveaus von Semaphorin 4D, Ephrin B2, BMP2, BMP6, SPHK1, HtrA1 und Wnt10b gemessen.

Ergebnisse Primäre mononukleäre Zellen wurden mithilfe von RANKL und M-CSF in Osteoklasten umgewandelt. Die Identifikation reifer Osteoklasten erfolgte anhand der erhöhten Expression von NFATc1 und TRAP zusammen mit dem Nachweis von mehr als 3 Zellkernen in der TRAP-Färbung. Die mRNA-Expressionsniveaus von BMP2, Ephrin B2 und SPHK1 waren nach Exposition gegenüber IL-23 um das 1,46-, 2,1- und 2,46-Fache erhöht. Die Bestätigung der erhöhten Konzentration von Ephrin B2 und SPHK1 in IL-23-stimulierten Osteoklasten erfolgte durch Western-Blot-Analyse. IL-23 hatte keine Auswirkungen auf die Expression von BMP6 oder Wnt10b oder auf die anti-osteogenen Faktoren Semaphorin 4D oder HtrA1.

Schlussfolgerungen IL-23 induziert Osteoklasten eher zur Expression pro-osteogener als anti-osteogener Faktoren, was darauf schließen lässt, dass IL-23 bei ankylosierender Spondylitis durch aktivierte Osteoklasten die Differenzierung von Osteoblasten fördern könnte.

\section{Introduction}

Ankylosing spondylitis (AS) is a spinal joint disease with typical symptoms of inflammatory back pain and affects about $0.3 \%$ of the Chinese population [1]. The pathological features of AS include enthesitis, erosion of bone and formation of new bone or syndesmophytes [2,3]. In patients with AS, clinical radiographs have shown unequivocally that erosions and sclerosis precede syndesmophyte development at the identified sites [4]. However, the underlying mechanisms for syndesmophyte formation in AS have not been fully elucidated.

IL-23 belongs to the interleukin-12 (IL-12) superfamily, and is released from dendritic cells and macrophages when they are activated [5]. Mediated by the downstream cytokines IL-22 and IL-17, IL-23 is vital in the functioning of the IL-17/IL-23 axis by facilitating Th17 cell differentiation. Thus, IL-23 plays a fundamental role in the pathophysiology of AS [6]. The levels of IL-23 and IL-17 were greatly increased in the sera of AS patients [7, 8]. Increased IL-23 levels in patients with active AS might be caused by a subclinical gut inflammation [9]. Also, more IL-23 was secreted in AS macrophages than healthy macrophages in response to lipopolysaccharide [10]. Moreover, IL-23 levels and Th17 cell numbers increased in the colon of HLA-B27 transgenic rats, an animal model of AS [11] and neutralizing anti-IL-23 antibody treatment was demonstrated to significantly alleviate peripheral arthritis and spondyloarthritis in the AS animal models [12]. Moreover, a critical study showed that mice with over-expression of IL-23 spontaneously phenocopied the human AS, with the specific and characteristic development of enthesitis and entheseal new bone formation [13]. Histological examination revealed many osteoblasts and multinucleated osteoclasts at the sites of entheseal inflammation. Taken together, these results indicate that IL-23 is involved in the pathogenesis of AS and induces entheseal new bone formation.

Osteoclasts are multinucleated cells derived from hematopoietic precursor cells in bone marrow and possess bone-resorbing properties. The precursor cells differentiate into mature osteoclasts when M-CSF and RANKL are present [14]. A number of studies have reported that IL-23 could promote the differentiation of osteoclasts through RANKL and that IL-23 might indirectly inhibit osteoclastogenesis through T cells [15-18]. Kamiya et al. [19] reported that no remarkable changes were observed in the expression of mRNA for type I collagen or ALP in osteoblasts after stimulation by IL-23, indicating that IL-23 had no direct actions on osteoblasts. We con- firmed that IL-23 had no direct effects on osteoblasts, since osteoblasts marginally express IL-23 receptors [20]. Taken together, the above data imply that IL-23 indirectly induces new bone formation at the sites of entheseal inflammation.

Bone homeostasis is tightly regulated by signaling pathways that act on osteoblasts and osteoclasts. In the physiological state, new bone formation and erosion occur simultaneously during the dynamic equilibrium of bone metabolism. On one hand, osteoblasts regulate the differentiation of osteoclasts by producing the essential differentiating factors RANKL and M-CSF and also osteoprotegerin (OPG), which is an inhibitory factor. On the other hand, osteoclasts promote the differentiation of osteoblasts by producing osteogenic factors such as the Eph family receptor interacting proteins B2 (Ephrin B2), sphingosine kinase 1 (SPHK1), bone morphogenetic proteins (BMP) and Wnt10b, and inhibit the differentiation of osteoblasts by producing anti-osteogenic factors Semaphorin 4D and high temperature requirement protease A1 (HtrA1) [21].

Considering the paradox between the significant induction of IL-23 on the formation of new bone and the fact that it has no direct effect on osteoblasts, we assumed that IL-23 might participate in the indirect regulation of osteoblast differentiation through osteoclasts. To elucidate the possible mechanisms involved, we investigated whether IL-23 could modulate the expression of Ephrin B2, SPHK1, BMP2, BMP6, Wnt10b, HtrA1 and semaphorin 4D in osteoclasts.

\section{Materials and Methods}

\section{Isolation of bone marrow mononuclear cells (BMMCs)}

Wild-type C57BL/6 mice (6-8 weeks) were obtained from Shanghai Jiao Tong University Laboratory Animal Center (Shanghai, China). The mice were humanely killed by inhalation of carbon dioxide and sterilized with $75 \%$ ethanol. Tibiae and femora were dissected after removing the skin and associated soft tissues. The epiphyses of the tibiae and femora were severed and bone marrow isolated by flushing with Hanks I solution. BMMCs were harvested after centrifugation, incubation with red blood cell lysis buffer, and washing with Hanks I solution. The ethical committee of the Second Military Medical University gave approval for all the experimental procedures. 


\section{Induction of osteoclasts}

The isolated primary BMMCs were cultured for 3 days at $37^{\circ} \mathrm{C}$ in the presence of humidified $5 \% \mathrm{CO}_{2} / 95 \%$ air in Dulbecco's modified Eagle medium (DMEM), to which had been supplied $50 \mu \mathrm{g} / \mathrm{mL}$ streptomycin, $50 \mathrm{U} / \mathrm{mL}$ penicillin, $10 \%$ fetal calf serum and $50 \mathrm{ng} / \mathrm{ml}$ M-CSF (PeproTech, US). Adherent cells were detached, plated onto 12-well plates at $5 \times 10^{5}$ cells per well and cultured for another 5-6 days supplied with RANKL ( $30 \mathrm{ng} / \mathrm{ml}$, R\&D, US) and M-CSF (50 ng/ $\mathrm{ml})$, which was replaced every $48 \mathrm{~h}$.

For osteoclast induction, murine RAW264.7 cells were also used and cultured in DMEM containing $30 \mathrm{ng} / \mathrm{ml} \mathrm{RANKL}$ for 5-6 days. The culture medium was replaced at $48 \mathrm{~h}$ intervals.

Based on previous studies [15-18], the concentration of IL-23 (PeproTech, USA) was selected as $30 \mathrm{ng} / \mathrm{ml}$ in all subsequent experiments. After identification, osteoclasts were refreshed with medium without RANKL or M-CSF, and treated with $30 \mathrm{ng} / \mathrm{ml} \mathrm{IL-23} \mathrm{for}$ the indicated times.

\section{TRAP staining}

After washing in PBS and then fixation in paraformaldehyde solution (4\%), the cells were stained for tartrate-resistant acid phosphatase (TRAP) with a commercial kit (Sigma, US). Using two specific osteoclast markers, multinucleated ( $>3$ nuclei) TRAP-positive cells were shown to be mature osteoclasts.

\section{RNA extraction and real-time RT-PCR}

Acid guanidine-phenol-chloroform and TRIzol (BBI sciences, US) was used to extract RNA from osteoclasts. First-strand cDNA was constructed from the extracted RNA using a Mix reverse transcription kit (Tiangen Inc., Beijing), and subsequently utilized as templates in PCR experiments. PCR amplification was carried out using the specific primers listed in $>$ Table 1 . The genes of interest were measured using real-time PCR (ABI ViiA7, Applied Biosystems, US) with a Power SYBR Green Master Mix (Life, US). The expression levels of genes relative to one another were analyzed using the $\Delta \Delta \mathrm{Ct}$ method. An expressed gene that encoded GAPDH was adopted as the internal control to normalize the quantities of mRNA present in each specimen.

\section{Western blotting}

Proteins were extracted by lysing the osteoclasts with RIPA buffer (Aksomics, Shanghai) and quantified by a bicinchoninic acid (BCA) assay kit (Beyotime, Shanghai). Protein extracts (equal quantities) were separated using $10 \%$ sodium dodecyl sulfate-polyacrylamide gel electrophoresis and were then transferred onto a PVDF membrane (Whatman, UK). PVDF membranes were blocked with no fat milk and incubated at $4{ }^{\circ} \mathrm{C}$ overnight with primary antibodies against GAPDH (Tianjin Sungene Biotech, China), Ephrin B2 (Abcam Inc., USA) and SPHK1 (Cell Signaling Technology Inc., USA) at a dilution of 1:1000. After washing 3 times, the PVDF membranes were incubated with HRP-conjugated secondary antibodies (1:3000; Santa Cruz Biotechnology, USA). Protein bands were visualized using ECL (Millipore, USA)and the densitometry readings were quantified using Image J software (NIH, USA).

\section{Statistical analyses}

Data are expressed as mean \pm SD and all calculations were carried out using SPSS for Windows (ver. 22.0, IBM SPSS Software, US). At-test
- Table 1 Primer sequences used in quantitative real-time PCR analysis.

\begin{tabular}{|c|c|}
\hline Gene & Primer \\
\hline \multirow{2}{*}{ BMP2 } & 5'-CCTTCGGAAGACGTCCTCAG-3' \\
\hline & 5'-CTGAGTGCCTGCGGTACAGA-3' \\
\hline \multirow{2}{*}{ BMP6 } & 5'-CTGCTGAGTTCCGCGTCTAC-3' \\
\hline & 5'-TCCAGCCAACCTTCTTCTGA-3' \\
\hline \multirow{2}{*}{ Ephrin B2 } & 5'-CGGACAAGGCCTGGTACTAT-3' \\
\hline & 5'-GTCTGGTCTGGCACAGTTGA-3' \\
\hline \multirow{2}{*}{ GAPDH } & 5'-GGTCGGTGTGAACGGATTTG-3' \\
\hline & 5'-TGTAGACCATGTAGTTGAGGTCA-3' \\
\hline \multirow{2}{*}{ HtrA1 } & 5'-AGCGACGCCAAGACCTACAC-3' \\
\hline & 5'-GGCGATCTTCTCCACCACAT-3' \\
\hline \multirow{2}{*}{ NFATc1 } & 5'-CCTGGAGATCCCGTTGC-3' \\
\hline & 5'-GGTGTTCTTCCTCCCGATGT-3' \\
\hline \multirow{2}{*}{ Semaphorin 4D } & 5'-GACAGTGGCCTGGTCTTCAA-3' \\
\hline & 5'-CACTGTGGCACTCTGCATGT-3' \\
\hline \multirow{2}{*}{ SPHK1 } & 5'-TTCCTGGAGGAGGCAGAGAT-3' \\
\hline & 5'-ACCATCACCGGACATGACTG-3' \\
\hline \multirow{2}{*}{ TRAP } & 5'-CGACCATTGTTAGCCACATACG-3' \\
\hline & 5'-TCGTCCTGAAGATACTGCAGGTT-3' \\
\hline \multirow[b]{2}{*}{ Wnt10b } & 5'-GGATGGCTGTAACCACGACAT-3' \\
\hline & 5'-GTTGTTGTGGATCCGCATTC-3' \\
\hline
\end{tabular}

$\mathrm{PCR}=$ polymerase chain reaction; $\mathrm{BMP}=$ bone morphogenetic protein; $\mathrm{GAPDH}=$ glyceraldehyde-3-phosphate dehydrogenase; HtrA 1 = high temperature requirement protease A1; NFATc $1=$ nuclear factor of activated T-cells cytoplasmic 1 ; SPHK $1=$ sphingosine kinase 1; TRAP = tartrate-resistant acid phosphatase.

was employed to assess differences between parametric data, and non-parametric data was analyzed using the Mann-Whitney test. P-value $<0.05$ was considered to represent significant findings.

\section{Results}

\section{Induction and identification of osteoclasts}

Osteoclasts are mainly produced from hematopoietic precursor cells (monocytes/macrophages lineage) in the bone marrow. RANKL triggers the development and subsequent activation of osteoclasts in vitro and in vivo [22]. When primary osteoclast precursors were cultured with both RANKL and M-CSF for 5-6 days, most of the precursors fused together and became TRAP positive with $>3$ nuclei. These TRAP-positive cells were much larger than the precursors, which were cultured with M-CSF alone ( $\mathbf{F i g . ~} \mathbf{1} \mathbf{a}$ and $\mathbf{b}$ ).

The RAW264.7 murine cell line is often used for in vitro studies of osteoclasts. They do not need M-CSF for their RANKL-induced transformation to osteoclasts [23]. Because of their ready access and availability, we also tried to induce osteoclasts from RAW264.7 cells cultured with RANKL ( $\triangleright$ Fig. $1 \mathbf{c}$ and $\mathbf{d}$ ). Due to the percentage of osteoclast differentiation induced from RAW264.7 cells was 


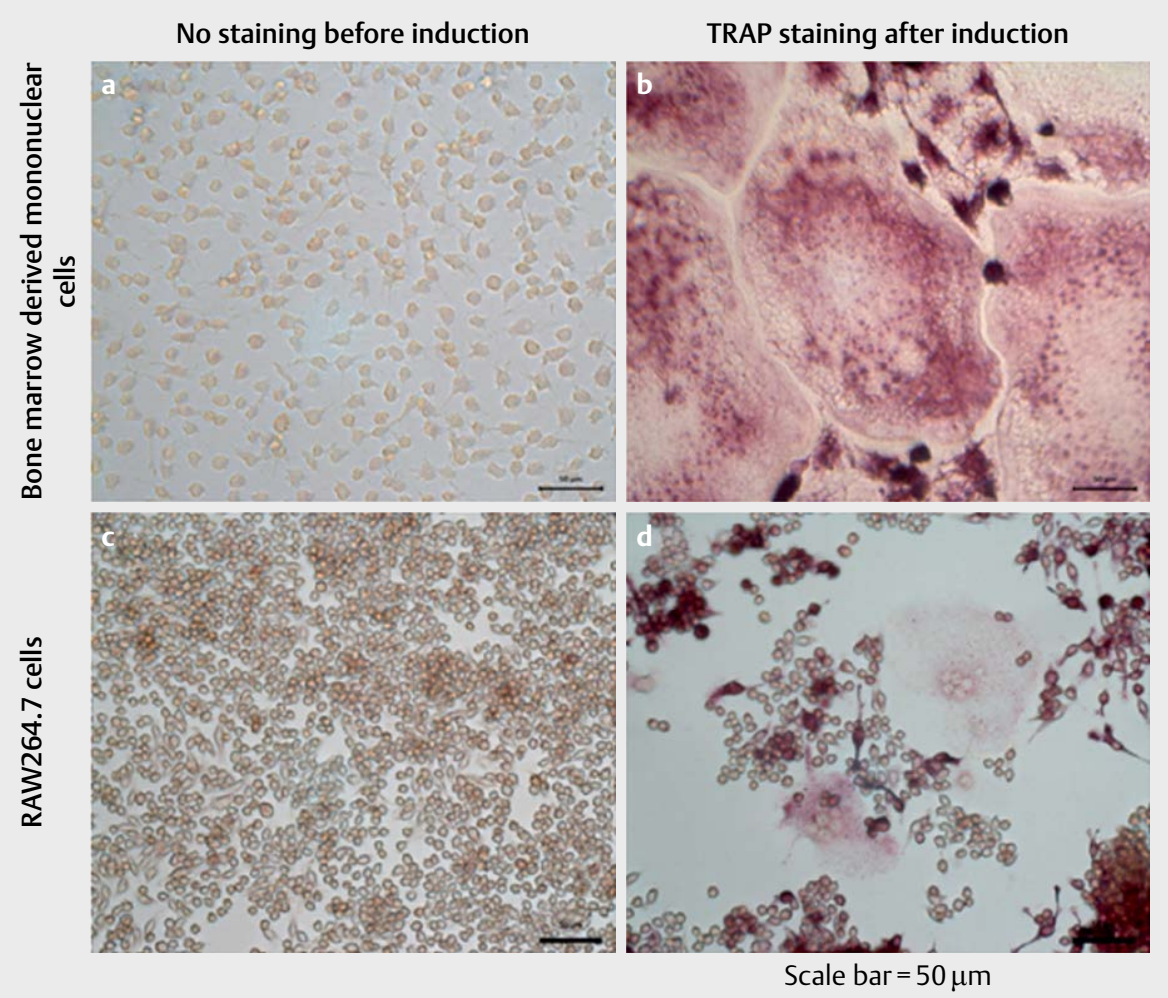

- Fig. 1 Identification of the induced osteoclasts by TRAP staining. a Primary mouse bone marrow mononuclear cells (BMMCs) were obtained by flushing femurs and tibias of 6- to 8-week-old C57/BL-6 mice and cultured in DMEM containing $10 \%$ fetal calf serum (FCS) in the presence of $50 \mathrm{ng} / \mathrm{ml}$ macrophage-colony stimulating factor (M-CSF). b Primary mouse BMMCs were cultured in DMEM containing $10 \% \mathrm{FCS}$ in the presence of $50 \mathrm{ng} / \mathrm{ml}$ $\mathrm{M}-\mathrm{CSF}$ and $30 \mathrm{ng} / \mathrm{ml}$ receptor activator of nuclear factor-KB ligand (RANKL) for 5-6 days. After fixation, the cells were stained for tartrate-resistant acid phosphatase (TRAP) with a commercial kit. c Murine RAW264.7 cells were cultured in DMEM containing $10 \%$ FCS. d Murine RAW264.7 cells were cultured in DMEM containing $10 \%$ FCS in the presence of $30 \mathrm{ng} / \mathrm{ml}$ RANKL for 5-6 days. Then the cells were fixed and stained for TRAP. The TRAP positive multinucleated ( $>3$ nuclei) cells are identified as mature osteoclasts. Scale bar $=50 \mu \mathrm{m}$.
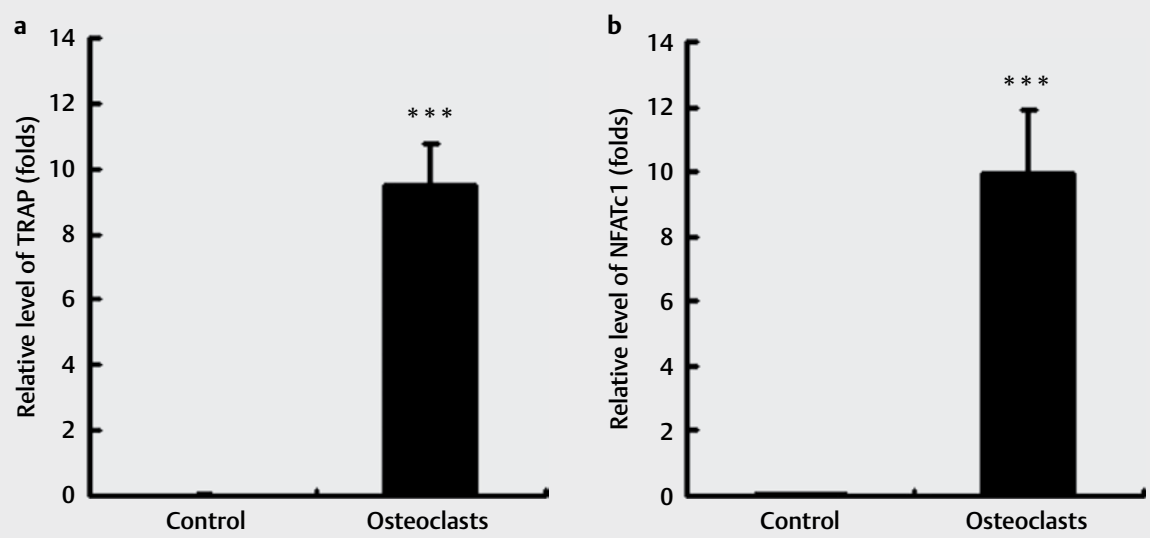

Fig. 2 The mRNA expression levels of TRAP and nuclear factor of activated T-cells cytoplasmic 1 (NFATc1) in induced osteoclasts. Primary mouse BMMCs were cultured in the presence of $50 \mathrm{ng} / \mathrm{ml} \mathrm{M}$-CSF alone (control) or in the presence of both $50 \mathrm{ng} / \mathrm{ml} \mathrm{M}$-CSF and $30 \mathrm{ng} / \mathrm{ml}$ RANKL (induced osteoclasts) for 5 days. Quantitative real-time PCR expression analysis was performed using a FastStart Universal SYBR Green Master with specific primers of TRAP $\mathbf{a}$ and NFATc1 $\mathbf{b}$. The constitutively expressed gene encoding glyceraldehyde-3-phosphate dehydrogenase $(\mathrm{GAPDH})$ was used for normalization. Data are expressed as the mean $\pm \mathrm{SD}(\mathrm{n}=4)$. Compared with the control cells, ${ }^{* * *} \mathrm{P}<0.001$. $>$ Fig. 1 for other definitions. 
lower than that from BMMCs, in the following experiments we only used osteoclasts induced from primary BMMCs.

Osteoclast bone resorption is detected by the activity of TRAP and associated enzymes. In the late stage of osteoclastogenic signaling, it is characterized by the amplification of NFATc1, whose function is to transcribe those genes that control the multi-nucleation and bone resorption functions of osteoclasts [14]. To confirm further the characteristics of osteoclasts, the expression levels of NFATc1 and TRAP mRNAs in BMMCs pre-treated with both RANKL and M-CSF were demonstrated to be much higher than inBMMCs pre-treated with M-CSF alone ( $\mathbf{F i g}$. 2).

\section{Stimulatory effects of IL-23 on the expression of pro-osteogenic factors in osteoclasts}

Compared with unstimulated osteoclasts, IL-23 significantly increased mRNA expression levels of Ephrin B2, SPHK1 and BMP2 ( $\triangleright$ Figs. 3a-c). Peak levels of Ephrin B2 and BMP2 occurred $3 \mathrm{~h}$ after stimulation with IL-23 and peak level of SPHK1 at $6 \mathrm{~h}$. In osteoclasts stimulated with IL-23, the maximal expression levels of mRNAs for BMP2, Ephrin B2 and SPHK1 were increased by 1.46, 2.1 and 2.46 folds, respectively. Increased protein levels of Ephrin B2 and SPHK1 were also demonstrated by Western blot ( $\triangleright$ Fig. 4). The maximal levels of SPHK1 and Ephrin B2 proteins were increased by 1.56 and 1.65 folds, respectively. Because of the limited elevation of mRNA expression levels of BMP2 after IL-23 stimulation, the protein level of BMP2 was not detected in the present study.

No changes in the levels of mRNA expression for BMP6 or Wnt10b after IL-23 stimulation were found (• Figs. 3d, e).

\section{Null effect of IL-23 on the expression of anti- osteogenic factors in osteoclasts}

When osteoclasts were stimulated with IL-23 for 3-24 h, the mRNA expression levels of Semaphorin 4D and HtrA1 remained unchanged ( $\triangleright$ Fig. 3f, g).
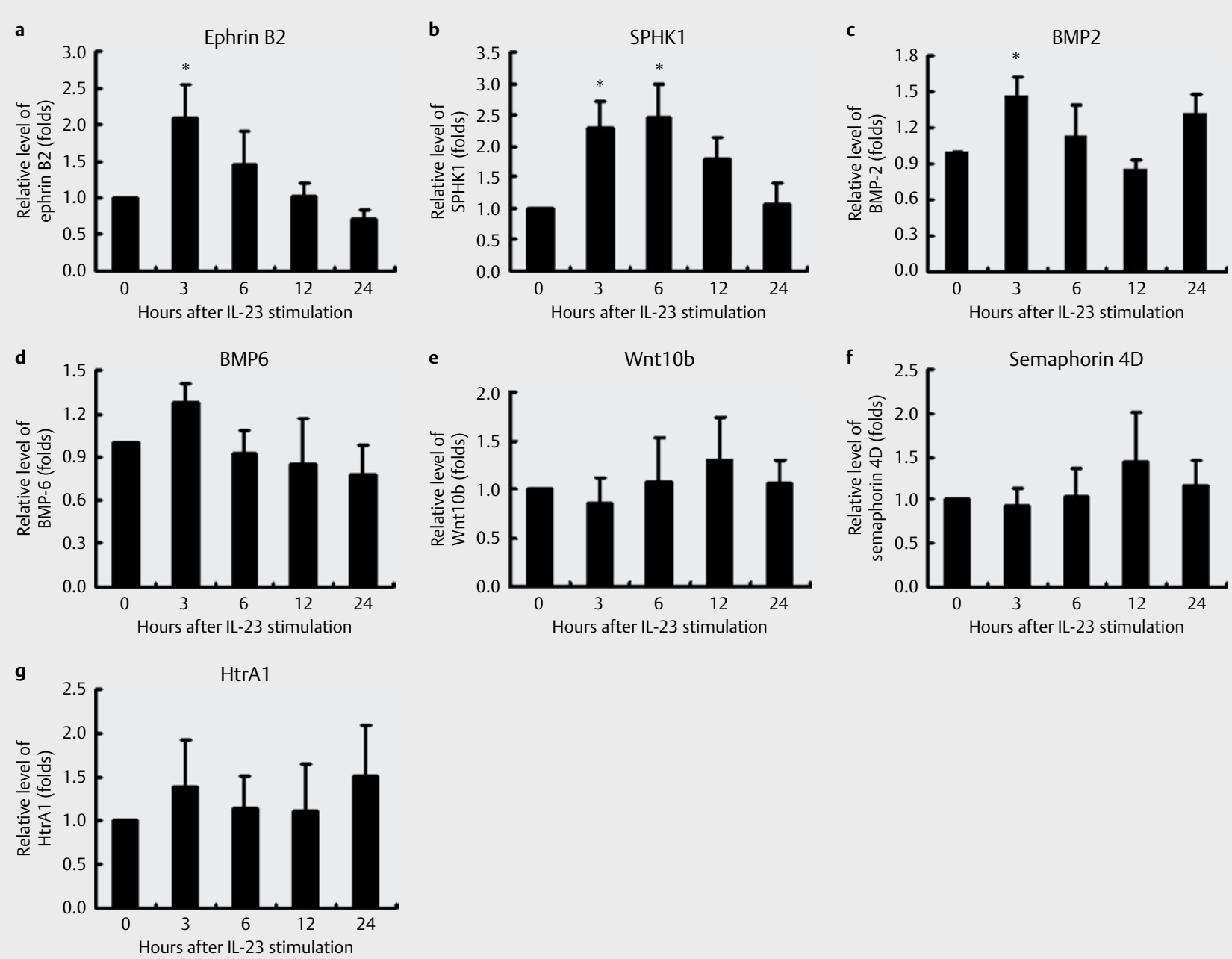

Fig. 3 Modulatory effects of IL-23 on the mRNA expression levels of pro-osteogenic and anti-osteogenic factors in osteoclasts. Osteoclasts were induced from primary mouse BMMCs in the presence of both $50 \mathrm{ng} / \mathrm{ml} \mathrm{M-CSF}$ and $30 \mathrm{ng} / \mathrm{ml}$ RANKL. The osteoclasts were refreshed with the medium without M-CSF or RANKL, and stimulated with a final concentration of $30 \mathrm{ng} / \mathrm{ml} \mathrm{IL-23} \mathrm{for} \mathrm{0-48} \mathrm{h.} \mathrm{Quantitative} \mathrm{real-time} \mathrm{PCR} \mathrm{expression} \mathrm{analysis} \mathrm{was}$ performed using specific primers of Ephrin B2 a, sphingosine kinase 1 (SPHK1, b), bone morphogenetic protein 2 (BMP2, c), BMP6 d, Wnt10b e, Semaphorin 4D $\mathbf{f}$ and high temperature requirement protease $A 1(\mathrm{HtrA} 1, \mathbf{g})$. Data are expressed as the mean \pm SD $(n=4)$. Compared with the osteoclasts without IL-23-stimulation, ${ }^{*} \mathrm{P}<0.05$. $>$ Fig. 1 for other definitions. 
a
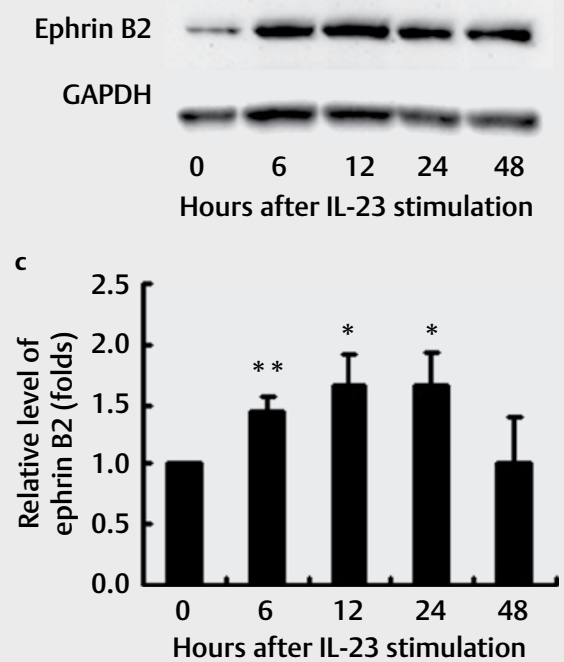

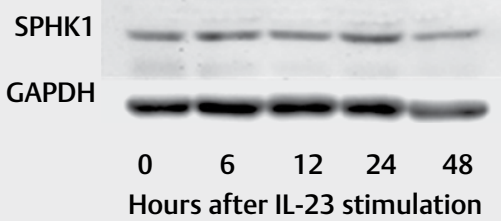

d

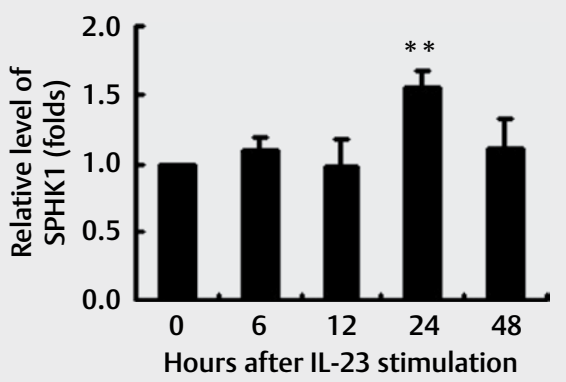

- Fig. 4 Stimulatory effects of IL-23 on the protein expression levels of Ephrin B2 and SPHK1 in osteoclasts. Osteoclasts were induced from primary mouse BMMCs in the presence of both $50 \mathrm{ng} / \mathrm{ml} \mathrm{M-CSF}$ and $30 \mathrm{ng} / \mathrm{ml}$ RANKL. The osteoclasts were refreshed with the medium without M-CSF or RANKL and stimulated with $30 \mathrm{ng} / \mathrm{ml} \mathrm{IL-23} \mathrm{for} \mathrm{0-48} \mathrm{h.} \mathrm{Western} \mathrm{blot} \mathrm{analysis} \mathrm{was} \mathrm{performed} \mathrm{with} \mathrm{specific} \mathrm{antibodies} \mathrm{against} \mathrm{Ephrin} \mathrm{B2} \mathrm{a,} \mathrm{SPHK1} \mathrm{b} \mathrm{and}$ GAPDH, and levels of Ephrin B2 $\mathbf{c}$ and SPHK1 d relative to GAPDH were quantitated. The bands were subjected to densitometry analysis with standardization to GAPDH. Results shown are representative of 4 independent experiments. Compared with the initial phase ( $0 \mathrm{~h}$ after stimulation), ${ }^{*} \mathrm{P}<0.05 ;{ }^{* *} \mathrm{P}<0.01$. $>$ Fig. 1 for other definitions.

\section{Discussion}

The pathology of AS often involves the entheses i. e. the regions where tendons, capsules and ligaments attach to bone, where involves inflammation, bone erosion, and then syndesmophyte (spur) formation [2]. There is increasing evidence that suggests a pivotal role for IL-23 in the pathophysiology of AS [7-13, 24, 25]. However, little is known about how IL-23 regulates new bone formation (syndesmophyte formation). In the present study, for the first time, we have demonstrated that IL-23 promotes the expression of pro-osteogenic factors in osteoclasts including Ephrin B2, SPHK1 and BMP2. In contrast, IL-23 had no detectable effects on the expression of Semaphorin 4D and HtrA1, which are well recognized as anti-osteogenic factors.

The remodeling of bone is complex. When bone is resorbed by active osteoclasts, new bone is formed by osteoblasts in the lacunae almost simultaneously. There is a strict regulation of osteoclast and osteoblast coupling in both space and time [26, 27]. During bone remodeling, osteoclasts and osteoblasts communicate directly and indirectly in a process termed the 'coupling mechanism'. Osteoclasts and osteoblasts communicate by using diffusible (paracrine) signals, cell-to-cell contact and interactions with the cellular bone matrix [21, 28, 29]. During the initial period of bone remodeling, osteoblasts can express MCP-1 and osteoclastogenic factors including RANKL and M-CSF, which control chemotaxis, differentiation and migration of osteoclasts. It is noteworthy that cell signaling by RANK can activate several downstream transcription factors of osteoclasts including AP-1 (c-Fos), NFATc1 and NF-kB before they differentiate into mature osteoclasts and can resorb bone [30-32]. Mature osteoclasts produce many molecules that trigger differentiation of osteoblasts including Wnt10b, BMP2, BMP6, and sphingosine-1-phosphate (produced by SPHK1), while HtrA1 is secreted during osteoclastogenesis and functions to inhibit differentiation of osteoblasts [33]. Ephrin B2 is expressed on the cell membrane of osteoclasts and interacts with EphB4, expressed on the membrane of osteoblasts. Ephrin B2/EphB4 binding produces bidirectional signals that promote differentiation of osteoblasts and inhibit osteoclastogenesis [34, 35]. Osteoclasts also express a membrane-bound factor called Semaphorin 4D that suppresses the formation of bone during bone resorption [36].

BMPs are members of the TGF $\beta$ superfamily of growth signaling molecules. BMPs, (particularly BMP-2), play vital roles in the generation of mature osteoblasts. Another mechanism involved in osteoblastogenesis is the Wnt signaling pathway. Canonical signaling either through Wnt10b or glycogen synthase kinase-3 (GSK3) inhibition has been shown to promote osteoblastogenesis [37].

Eph receptors (EphRs) are tyrosine kinases that are activated by Ephrins and are classified into EphBs (EphB1-B6) and EphAs (EphA1-A8), whose membrane-anchored ligands are Ephrin Bs (Ephrin B1-B3) and EphrinAs (Ephrin A1-A6), respectively. The bidirectional signaling between Ephrin B2 and EphB4 exhibit significant functions in bone metabolism. Ephrin B2, which is expressed on the osteoclast cell surface membrane, activates Ephrin-Eph bidirectional signaling in osteoblasts and elicits differentiation of osteoblasts. The contra signal from EphB4 inhibits the formation of osteoclasts. Forward signaling through EphB4 into osteoblasts also enhances mineralization [35, 38].

SPHK 1 is the rate-limiting enzyme for the catalysis of sphingosine-1-phosphate. SPHK1 is upregulated in mature osteoclasts, but lower levels in precursor cells, indicating that SPHK1-produced sphingosine-1-phosphate may be elevated and playing an active 
role. Sphingosine-1-phosphate is an essential secreted coupling factor $[39,40]$. In osteoblasts, sphingosine-1-phosphate interacting with its receptors promotes osteoblast migration and survival. It also promotes osteoblast differentiation by activating Wnt/B-catenin and BMP2 signaling.

Semaphorin 4D expressed in osteoclasts binds to its receptor Plexin-B1 on osteoblasts, and exerts inhibition of bone formation [36]. $\mathrm{HtrA}$ proteins are serine proteases of which four distinct forms have been characterized, namely HtrA1, HtrA2, HtrA3 and HtrA4. During osteoclastogenesis induced by RANKL, HtrA1 is markedly upregulated and acts to limit osteoblast differentiation [33]. When HtrA1 is overexpressed it negatively regulates the mineralization of osteoblasts.

IL-23 plays important roles in the development of experimental autoimmune disease models and numerous afflictions affecting humans [24]. Genetic evidence links the IL-23/IL-17 pathway to inflammation in these rheumatic diseases, and mechanistic data from mice support a functional role for IL-23/IL-17 pathway activation in the development of enthesitis and in entheseal bone formation [25]. Furthermore, analysis of human tissue samples, as well as data from clinical trials, also supports a role for activation of the pathway in these diseases. However, Two placebo-controlled, double-blind clinical trials in axial spondyloarthritis (axSpA) of monoclonal antibodies directed against either the $\mathrm{p} 40$ protein or the $\mathrm{p} 19$ protein of the IL-23 molecule had no significant efficacy, but whether the treatment has an effect on new bone formation is still unknown for the slow radiographic progression unable to be observed in trial duration [41]. So, more studies are necessary to clarify the possible mechanism of IL-23 in bone formation.

In the present study, IL-23 significantly upregulated protein and mRNA levels of Ephrin B2, a membrane bound factor on the surface of osteoclasts. IL-23 also significantly upregulated both mRNA and protein levels of SPHK1 in osteoclasts. Both Ephrin B2 and SPHK1 have the potential to promote osteoblast differentiation, migration, survival and even mineralization. Although Semaphorin 4D and HtrA1 exert inhibitory effects on osteoblast differentiation, IL-23 had no detectable effects on HtrA1 and Semaphorin 4D expression. Thus IL-23 triggers osteoclasts to produce pro-osteogenic factors, indicating that IL-23 might indirectly promote the differentiation of osteoblasts via activated osteoclasts in AS.

\section{Author Contributions}

Dan-Dan Pang: performance and data collection of the experiments; Li Cai: manuscript drafting; Jing-Ru Zhang: statistical analysis, data collection and interpretation of data; Sheng-Ming Dai: conceive and design of the study, and revision of the manuscript.

\section{Funding}

S.M. Dai was supported by a grant from National Natural Science Foundation of China (No. 81471604) and a grant from National Key Basic Research Program of China (2014CB541804).

\section{Conflicts of Interest}

The authors declare that they have no competing interests.
References

[1] Xiang Y], Dai SM. Prevalence of rheumatic diseases and disability in China. Rheumatol Int 2009; 29: 481-490

[2] Lories R], Schett G. Pathophysiology of new bone formation and ankylosis in spondyloarthritis. Rheum Dis Clin North Am 2012; 38: 555-567

[3] Tam LS, Gu J, Yu D. Pathogenesis of ankylosing spondylitis. Nat Rev Rheumatol 2010; 6: 399-405

[4] Ramiro S, van Tubergen A, van der Heijde D et al. Brief report: erosions and sclerosis on radiographs precede the subsequent development of syndesmophytes at the same site: A twelve-year prospective followup of patients with ankylosing spondylitis. Arthritis Rheumatol 2014; 66: 2773-2779

[5] Layh-Schmitt G, Colbert RA. The interleukin-23/interleukin-17 axis in spondyloarthritis. Curr Opin Rheumatol 2008; 20: 392-397

[6] Sherlock JP, Buckley CD, Cua DJ. The critical role of interleukin-23 in spondyloarthropathy. Mol Immunol 2014; 57: 38-43

[7] Mei Y, Pan F, Gao J et al. Increased serum IL-17 and IL-23 in the patient with ankylosing spondylitis. Clin Rheumatol 2011; 30: 269-273

[8] Romero-Sanchez C, Jaimes DA, Londono J et al. Association between Th-17 cytokine profile and clinical features in patients with spondyloarthritis. Clin Exp Rheumatol 2011; 29: 828-834

[9] Ciccia F, Accardo-Palumbo A, Rizzo A et al. Evidence that autophagy, but not the unfolded protein response, regulates the expression of IL-23 in the gut of patients with ankylosing spondylitis and subclinical gut inflammation. Ann Rheum Dis 2014; 73: 1566-1574

[10] Zeng L, Lindstrom M], Smith JA. Ankylosing spondylitis macrophage production of higher levels of interleukin-23 in response to lipopolysaccharide without induction of a significant unfolded protein response. Arthritis Rheum 2011; 63: 3807-3817

[11] DeLay ML, Turner M], Klenk El et al. HLA-B27 misfolding and the unfolded protein response augment interleukin-23 production and are associated with Th17 activation in transgenic rats. Arthritis Rheum 2009; 60: 2633-2643

[12] Ruutu M, Thomas $G$, Steck R et al. Beta-glucan triggers spondylarthritis and Crohn's disease-like ileitis in SKG mice. Arthritis Rheum 2012; 64: 2211-2222

[13] Sherlock JP, Joyce-Shaikh B, Turner SP et al. IL-23 induces spondyloarthropathy by acting on ROR-gammat + CD3 + CD4-CD8- entheseal resident T cells. Nat Med 2012; 18: 1069-1076

[14] Park JH, Lee NK, Lee SY. Current Understanding of RANK Signaling in Osteoclast Differentiation and Maturation. Mol Cells 2017; 40: 706-713

[15] Chen L, Wei XQ, Evans B et al. IL-23 promotes osteoclast formation by up-regulation of receptor activator of NF-kappaB (RANK) expression in myeloid precursor cells. Eur J Immunol 2008; 38: 2845-2854

[16] Ju JH, Cho ML, Moon YM et al. IL-23 induces receptor activator of NF-kappaB ligand expression on CD4 + T cells and promotes osteoclastogenesis in an autoimmune arthritis model. J Immunol 2008; 181: 1507-1518

[17] Quinn JM, Sims NA, Saleh H et al. IL-23 inhibits osteoclastogenesis indirectly through lymphocytes and is required for the maintenance of bone mass in mice. J Immunol 2008; 181: 5720-5729

[18] Yago T, Nanke Y, Kawamoto M et al. IL-23 induces human osteoclastogenesis via IL-17 in vitro, and anti-IL-23 antibody attenuates collagen-induced arthritis in rats. Arthritis Res Ther 2007; 9: R96

[19] Kamiya S, Nakamura C, Fukawa T et al. Effects of IL-23 and IL-27 on osteoblasts and osteoclasts: Inhibitory effects on osteoclast differentiation. J Bone Miner Metab 2007; 25: 277-285

[20] Zhang JR, Pang DD, Tong Q et al. Different modulatory effects of IL-17, IL-22, and IL-23 on osteoblast differentiation. Mediators Inflamm $2017 ; 5950395$ 
[21] Kular J, Tickner J, Chim SM et al. An overview of the regulation of bone remodelling at the cellular level. Clin Biochem 2012; 45: 863-873

[22] Chambers T]. Regulation of the differentiation and function of osteoclasts. J Pathol 2000; 192: 4-13

[23] Hsu H, Lacey DL, Dunstan CR et al. Tumor necrosis factor receptor family member RANK mediates osteoclast differentiation and activation induced by osteoprotegerin ligand. Proc Natl Acad Sci USA 1999; 96: 3540-3545

[24] Razawy W, van Driel M, Lubberts E. The role of IL-23 receptor signaling in inflammation-mediated erosive autoimmune arthritis and bone remodeling. Eur J Immunol 2018; 48: 220-229

[25] Suzuki E, Mellins ED, Gershwin ME et al. The IL-23/IL-17 axis in psoriatic arthritis. Autoimmun Rev 2014; 13: 496-502

[26] Martin TJ, Sims NA. Osteoclast-derived activity in the coupling of bone formation to resorption. Trends Mol Med 2005; 11: 76-81

[27] Phan TC, Xu J, Zheng MH. Interaction between osteoblast and osteoclast: impact in bone disease. Histol Histopathol 2004; 19: 1325-1344

[28] Lieben L. Bone: Direct contact between mature osteoblasts and osteoclasts. Nat Rev Rheumatol 2018 Feb 15; doi:10.1038/nrrheum.2018.16. [Epub ahead of print]

[29] Florencio-Silva R, Sasso GR, Sasso-Cerri E et al. Biology of bone tissue: Structure, function, and factors that influence bone cells. Biomed Res Int 2015; 421746

[30] Takayanagi H, Kim S, Koga T et al. Induction and activation of the transcription factor NFATc1 (NFAT2) integrate RANKL signaling in terminal differentiation of osteoclasts. Dev Cell 2002; 3: 889-901

[31] Li ], Sarosi I, Yan XQ et al. RANK is the intrinsic hematopoietic cell surface receptor that controls osteoclastogenesis and regulation of bone mass and calcium metabolism. Proc Natl Acad Sci USA 2000; 97: 1566-1571
[32] Kong YY, Yoshida H, Sarosi I et al. OPGL is a key regulator of osteoclastogenesis, lymphocyte development and lymph-node organogenesis. Nature 1999; 397: 315-323

[33] Wu X, Chim SM, Kuek V et al. HtrA1 is upregulated during RANKLinduced osteoclastogenesis, and negatively regulates osteoblast differentiation and BMP2-induced Smad1/5/8, ERK and p38 phosphorylation. Febs Lett 2014; 588: 143-150

[34] Martin TJ, Allan EH, Ho PW et al. Communication between ephrinB2 and EphB4 within the osteoblast lineage. Adv Exp Med Biol 2010; 658: 51-60

[35] Zhao C, Irie N, Takada Y et al. Bidirectional ephrinB2-EphB4 signaling controls bone homeostasis. Cell Metab 2006; 4: 111-121

[36] Negishi-Koga T, Shinohara M, Komatsu $\mathrm{N}$ et al. Suppression of bone formation by osteoclastic expression of semaphorin 4D. Nat Med 2011; 17: 1473-1480

[37] Lin GL, Hankenson KD. Integration of BMP, Wnt, and notch signaling pathways in osteoblast differentiation. J Cell Biochem 2011; 112: 3491-3501

[38] Matsuo K, Otaki N. Bone cell interactions through Eph/ephrin: bone modeling, remodeling and associated diseases. Cell Adhes Migr 2012; 6: $148-156$

[39] Ishii M, Egen JG, Klauschen F et al. Sphingosine-1-phosphate mobilizes osteoclast precursors and regulates bone homeostasis. Nature 2009; 458: 524-528

[40] Meshcheryakova A, Mechtcheriakova D, Pietschmann P. Sphingosine 1-phosphate signaling in bone remodeling: multifaceted roles and therapeutic potential. Expert Opin Ther Tar 2017; 21: 725-737

[41] Sieper J, Poddubnyy D, Miossec P. The IL-23-IL-17 pathway as a therapeutic target in axial spondyloarthritis. Nat Rev Rheumatol 2019; 15: $747-757$ 